\title{
The management of patients with inflammatory smear results in general practice
}

\author{
Christine M Bates
}

\begin{abstract}
Object-To ascertain the management of inflammatory smear results by general practitioners.

Design-Postal questionnaire survey. Subjects-All 200 general practitioners on Wirral Family Health Services Authority list as principals in 1990 and 1991.
\end{abstract}

Main outcome measures-Answers to questions covering a variety of aspects concerning the management of inflammatory smear results in general practice. Results-One hundred and thirteen $(57 \%)$ replied. Ninety per cent have facilities to test for Trichomonas vaginalis and Candida albicans. Sixty eight per cent were able to test for Chlamydia trachomatis. A high vaginal swab (HVS) was the commonest swab taken $(88 \%)$; $31 \%$ of doctors included a swab for Chlamydia trachomatis. Of doctors who gave treatment without microbiological confirmation $\mathbf{7 4 \%}$ gave metronidazole and $64 \%$ gave tetracycline or erythromycin. Eighty five per cent repeat smears are undertaken within three months. Ninety seven per cent of doctors said more detailed information would be helpful on the cytology report. One hundred per cent of doctors referred to a gynaecologist if colposcopy was advised. Male sexual partners were advised to attend the Department of Genitourinary Medicine by $12 \%$ of doctors ( $70 \%$ do not refer to either their general practitioner or genitourinary department).

Conclusion-Most patients with inflammatory smear results are managed by their general practitioner without reference to specialist services. Many patients are not investigated for infection but treatment often includes medication which covers the most likely or potentially serious genital pathogens. More detailed advice given with the cytology report on further management or a local protocol would be helpful to aid management in this difficult area. If recommendations for referral of certain groups of patients to genitourinary departments were implemented the present workload of the department would be increased.

(Genitourin Med 1993;69:126-129)

\section{Introduction}

Inflammatory changes on cervical cytology are not infrequently associated with sexually transmitted infection ${ }^{1}$ and it is well recognised that more than one sexually transmitted disease may coexist making screening for other infections advisable. ${ }^{2}$

Cytopathological appearances on the Papanicolau smear may suggest specific pathogens: Trichomonas vaginalis, candida species, Gardnerella vaginalis, human papilloma virus, Chlamydia trachomatis and herpes simplex virus, but the sensitivity and specificity in respect of Chlamydia trachomatis is disputed. . $^{3-6}$

As a result of the British Society for Clinical Cytology working party recommendation $^{7}$ abnormal smear results are accompanied by advice on management; for example, "investigate, treat and repeat" is now added to a report where inflammatory changes are seen on cervical cytology.

A recent study in the community ${ }^{8}$ found $5 \%$ of smears taken in one year in one general practice were reported as inflammatory, almost half of which had microbiologically proven infection when subsequently investigated, the commonest infecting organisms being gardnerella and candida, which agrees with the findings of an earlier study in general practice. ${ }^{9}$

In another community based study where patients with inflammatory smears were referred to a department of genitourinary medicine for investigation, genital infection was found in three quarters, a fifth of whom had coexistent infection. ${ }^{1}$ The prevalence of Chlamydia trachomatis in this study was $18 \%$ (previous studies have shown prevalences of $5.7 \%-7.3 \%) .^{9-12}$

In view of this the authors suggested that, notwithstanding the constraints of the service, certain categories of patients should be referred to departments of genitourinary medicine for further investigation whilst the remaining patients (such as those under 25 years of age or with recent change in sexual partner) should have a repeat smear, and be referred should the result again be unsatisfactory. This is much the same as the suggested management by Singer. ${ }^{13}$

A survey was undertaken of general practitioners in the Wirral Area to ascertain the usual management of patients with inflammatory smears and to see how this compared with recent recommendations. ${ }^{13}$ If there is a
Wirral, Merseyside,

L49 5PE

Accepted for publication 21 October 1992 
great divergence of practice this has implications for possible changes in the workload of various departments, including hospital departments of genitourinary medicine (GUM), gynaecology, cytology and microbiology as well as general practitioners themselves, should these recommendations be implemented. It also has implications for the patients and their sexual partners who may not be adequately investigated, treated and followed up, which, especially in terms of Chlamydia trachomatis, may have long-term sequelae.

\section{Method}

General practitioners $(n=200)$ on the Wirral Family Health Authority list were sent a postal questionnaire during the period December 1990 to March 1991. The questionnaire asked doctors to state what facilities they had for routinely taking swabs for vaginal and cervical infections and in what circumstances they would include swabs for infection when taking a routine cervical smear.

Doctors were asked how patients were made aware of abnormal smear results and what arrangements are made for further follow-up. Also, how important they thought screening for sexually transmitted diseases was in patients with inflammatory smears and what investigations, if any, were undertaken if such a report was received. They were asked if they screened for additional genital infections if a specific infection such as Trichomonas vaginalis or candida was reported by the cytology laboratory.

Doctors were asked to indicate what treatment, if any, was given and how long they would wait before a repeat smear was performed. Views on advice given in smear reports were obtained, as was the likely choice for referral if colposcopy was advised. Doctors were asked whether they recommended that the male sexual partners of patients with inflammatory smears consult either their own general practitioner or the genitourinary medicine department. Finally, comments regarding the management of an abnormal smear result were invited.

\section{Results}

A total of $113(57 \%)$ replies were received, one of which was excluded as the doctor stated that he did not deal with smears in his practice. Of the remaining 112 , table 1 shows their facilities, including swabs, transport media and access to laboratory for routine testing for genital infection. Almost all doctors are able to investigate for common vaginal pathogens such as Trichomonas vaginalis and candida, and $68 \%$ can test for Chlamydia trachomatis. A third are able to take specimens for Neisseria gonorrhoeae whilst $15 \%$ can test for herpes simplex virus. Six reported that they had no facilities at all.

When taking an initial routine cervical smear three doctors also undertook investiga-
Table 1 Genital infections for which 112 doctors had facilities to investigate

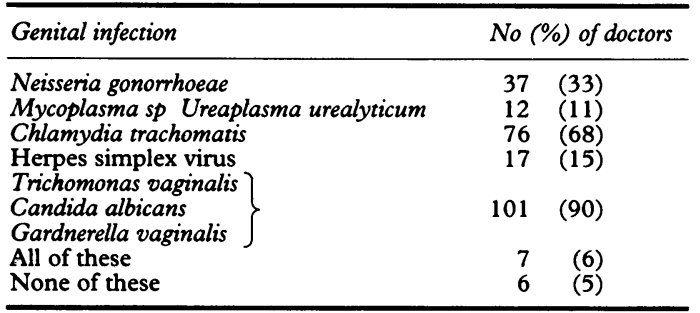

tion to exclude genital infection; $97(87 \%)$ said they would do so if the patient had symptoms whilst $57(51 \%)$ would take swabs if the patient's sexual partner had a sexually transmitted infection and $64(59 \%)$ would if the previous smear showed an infection.

Patients were made aware of abnormal results either by being asked to contact the surgery themselves [39 (35\%)] or by direct contact by telephone or letter by the doctor or practice nurse [69 (62\%)]. In both cases the patient is usually asked to make an appointment to discuss the result with the doctor. One doctor relied solely on the Family Health Services Authority (FHSA) to contact the patient; nine others cited this as an additional method. Where the patient had been asked to make contact most doctors added that if they had not done so within a month or if referral had been recommended the practice would then contact the patient instead.

Follow-up was ensured by $33(30 \%)$ doctors using their own computer recall system, $44(40 \%)$ using a manual recall system of either a diary, tagging notes or keeping a separate list of abnormal results; five (5\%) relied on the FHSA computer recall; $16(15 \%)$ relied on the patient to ensure their own follow up having explained the need for this. Eleven $(10 \%)$ of doctors did not specify how they followed patients up.

Attitudes to the importance of screening for sexually transmitted diseases (STDs) in patients with inflammatory smears covered a range of views: $16(14 \%)$ doctors thought it obligatory, $54 \%$ desirable but not essential; $30 \%$ unlikely to be cost effective; 9 did not express a view.

Table 2 shows what investigations are undertaken if a report of "inflammatory cells, investigate, treat and repeat" is received.

The swab most commonly taken is that of high vaginal swab (HVS): $99(88 \%)$ of respondents cite this as one they would take. Forty eight of the 112 said an HVS would be

Table 2 Investigations undertaken by doctors when a report of inflammatory cells, investigate, treat and repeat is received

\begin{tabular}{|c|c|}
\hline Investigation undertaken & No (\%) of doctors \\
\hline $\begin{array}{l}\text { High vaginal swab (HVS) only. } \\
\text { HVS }\end{array}$ & $48 \quad(43)$ \\
\hline $\begin{array}{c}\text { Urethral swabs for } N \text { gonorrhoeae } \\
\text { Cervical swabs Chlamydia trachomatis } \\
\text { herpes simplex virus }\end{array}$ & (2) \\
\hline $\begin{array}{l}\text { Cervical swab for Chlamydia trachomatis } \\
\text { HVS and cervical swab for. } N \text { gonorrhoeae } \\
\text { Swabs including HVS } \\
\text { No investigation undertaken }\end{array}$ & $\begin{array}{rr}35 & (31) \\
13 & (12) \\
99 & (88) \\
6 & (5)\end{array}$ \\
\hline
\end{tabular}


the only swab they would take. Two replied that urethral and cervical swabs for Neisseria gonorrhoeae, Chlamydia trachomatis, an HVS and a cervical swab for herpes simplex virus would all be taken. Thirty one per cent of doctors included a swab for Chlamydia trachomatis usually in addition to an HVS. Six stated that they would take no swabs.

Asked if they screened routinely for other STDs if a specific infection (such as Trichomonas vaginalis or Candida albicans) was reported as being seen on a cervical smear, eight $(7 \%)$ said they would; 100 $(89 \%)$ would not, although six of these said they sent patients to the genitourinary medicine department for further investigation. Sixty six $(59 \%)$ said they would screen for other STDs only if the patients had symptoms; $36(32 \%)$ would not look for coincidental infections at all.

When a patient was reported to have an inflammatory smear $27(24 \%)$ doctors treated blind without waiting for microbiological confirmation of infection; $53(47 \%)$ waited for results of swabs whilst $31(28 \%)$ practise a combination of methods depending on clinical circumstances.

Of those treating blind at any point a wide variation of preparations are prescribed; metronidazole was the commonest choice; 43 out of 58 doctors $(74 \%)$ said they used this usually in combination with an antifungal agent.

Thirty seven $(64 \%)$ replied that they gave either tetracycline or erythromycin (both effective against chlamydial infection) again usually in combination with either metronidazole and/or an antifungal agent.

Six gave antifungal agents alone, four gave metronidazole alone and one doctor used sultrin only. Three used cephalosporins in combination with metronidazole and one gave betadine pessaries with metronidazole. Table 3 lists the medication used to treat patients with inflammatory smear results without microbiological evidence of infection.

Table 4 shows the time allowed to elapse

Table 3 Medication prescribed before microbial confirmation. Figures are numbers (percentage) of 58 doctors who "treat blind".

\begin{tabular}{lrc}
\hline Medication & \multicolumn{3}{c}{ No (\%) doctors } \\
\hline Tetracycline & 13 & $(22)$ \\
Erythromycin & 24 & $(41)$ \\
Antifungal & 33 & $(57)$ \\
Metronidazole & 43 & $(74)$ \\
Cephalosporin & 3 & $(5)$ \\
Penicillin or derivative & 2 & $(3)$ \\
Vaginal Antibacterial Cream & 2 & $(3)$ \\
$\quad$ (Sultrin Betadine) & & \\
\hline
\end{tabular}

Table 4 Time allowed to elapse before repeat smear is performed. Figures are number (percentage) of 109 doctors who responded

\begin{tabular}{|c|c|c|c|}
\hline Time in months & No (\%) of & tors & \\
\hline$<3$ & $66 \quad(61)$ & \multirow{2}{*}{\multicolumn{2}{|c|}{$93 \quad(85)$}} \\
\hline $\begin{array}{l}3 \\
3-6 \\
6 \\
12 \\
\end{array}$ & $\begin{array}{rr}27 & (25) \\
5 & (5) \\
10 & (9) \\
1 & (1)\end{array}$ & & \\
\hline
\end{tabular}

before repeat smears are performed. This ranges from three weeks to one year, the majority being performed within three months. Twenty four doctors said that they followed the laboratory recommendation (normally repeating the smear 2-6 weeks after treatment) and two of these relied on computer recall by the FHSA.

Of 109 doctors who replied, 79 (72\%) felt that the advice on further management given on the smear report was clinically relevant and helpful; 29 (27\%) were not satisfied. One hundred and six (97\%) answered that more detailed advice, for example, a suggestion of the likely pathogen, would be desirable.

Doctors were asked where they referred patients when colposcopy was advised on the smear report; three general practitioners failed to answer this part of the questionnaire. Of the remaining 109 doctors $109(100 \%)$ referred the patient to a gynaecologist. Additionally, three occasionally referred the patient to a GUM department and one specified colposcopy clinic.

Concerning male sexual partners of patients with inflammatory smears, 76 (70\%) doctors said they would not ask them to visit either their family doctor or the GUM department. Thirty one (28\%) doctors would ask them to attend their own family doctor (of these 13 would alternatively ask them to attend the GUM department). In total 94 $(86 \%)$ would not ask them to attend the GUM department. Again, three doctors failed to answer this question.

Finally, general comments on the subject of inflammatory smear results were invited and these are considered in the discussion.

\section{Discussion}

The majority of doctors replying to the questionnaire have facilities for testing for the commoner genital pathogens such as Candida albicans, Trichomonas vaginalis, Gardnerella vaginalis and Chlamydia trachomatis (two doctors reported difficulty in obtaining Chlamydia transport medium in sufficient quantity to allow routine testing for chlamydia). Despite seemingly adequate facilities only $14 \%$ of doctors felt that screening for STDs in patients with inflammatory smears is essential. When investigation is undertaken an HVS is cited as the only swab taken by almost half the doctors. According to studies in the community the commonest microbiologically proven infections are gardnerella and candida. ${ }^{89}$ The prevalence of Chlamydia trachomatis has been reported as ranging from 5.7 - 18\%. ${ }^{19-12}$ More than two thirds of respondents did not include swabs for Chlamydia trachomatis in these investigations despite the fact that $68 \%$ reported that they had facilities to do so. This could mean that a small but significant number of infections are missed. However, this seems unlikely as the majority $(64 \%)$ of doctors treating a patient with an inflammatory smear (without microbiological confirmation) include medication which is effective against chlamydia. 
It is a well recognised fact in GUM departments that more than one STD may coexist and that screening for other infections is desirable. Eighty nine per cent of doctors replied that they would not routinely do this, although six of these would send the patient to the GUM department. Even if the patient was symptomatic 36 doctors said that they would not look for coexistent infections.

When colposcopy is advised by the cytology laboratory, without exception all respondents refer the patient to a gynaecologist for further management. (Only three doctors said they occasionally referred to the GUM Department.) Referral patterns will reflect the local arrangements between gynaecology and GUM department and availability of the service provided although also it may indicate that it is less acceptable to general practitioners and their patients to attend the GUM department than a gynaecology clinic or a colposcopy clinic run by gynaecologists. One doctor queried how acceptable cervical cytology as a screening test would remain if patients with inflammatory smears (an increasing proportion of smears taken in the practice in his experience) were to be investigated for STDs.

Only a minority of doctors said they would advise the male sexual partners of patients with inflammatory smears to be checked; of these most preferred to send them to their own general practitioner rather than the GUM department. Factors may include the perceived stigma of attending a GUM clinic or the implication of doing so, for example, where questions on life insurance forms may relate to past attendance or treatment of STD at a GUM clinic.

Many doctors used the questionnaire as an opportunity to air their concern regarding the management of inflammatory smears. The apparent commonality of the inflammatory smear report and the impression that it often may return to normal on repeat testing was mentioned by several doctors. Ten doctors asked if a protocol for management could be drawn up or if more specific help in the likely cause of infection could be given. It is apparent that few patients, or their partners, are referred to GUM departments following an inflammatory smear report for investigation. It would, therefore, seem prudent that, if patients are to be managed by their general practitioner that guidelines be issued, either as a local protocol or possibly in the form of a notice attached to the smear report, with regard to further investigation and treatment with and indication as to when referral to a GUM Department might be appropriate.

I thank Dr IA Tait and Dr AK Ghosh for their advice and encouragement and Mrs Mary Percy and Mrs Amanda Jelley for their invaluable secretarial support.

1 Wilson JD, Robinson AJ, Kinghorn SA, Hicks DA Implications of inflammatory changes on cervical cytology. BMF 1990;300:638-40.

2 Carne CA, Dockerty G. Genital warts; need to screen for coinfection. $B M F$ 1990;300:459.

3 Werness BA. Cytopathology of sexually transmitted disease. Clin Lab Med 1989;9:559-72.

4 Sekhri A, Le Faou AE, Tardieu JC, Antz M, Fabre M. What can be expected from the cytologic examination of cervicovaginal smears for the diagnosis of Chlamydia tracervicovaginal smears for the diagnosis of Chlamy
chomatis infection? Acta Cytol 1988;32:805-10

5 Ghirardini C, Boselli F, Messi P, Rivasi F, Trentini GP. Chlamydia trachomatis infection in asymptomatic women. Results of a study employing different staining techniques. Acta Cytol 1989;33:115-9.

6 Arroyo G, Linnemann C, Wesseler T. Role of Papanincolaou smear in diagnosis of chlamydial infections. Sex Transm Dis 1989;16:11-4.

7 Sharp F, Duncan ID, Evans DMD, et al. Report of the Intercollegiate Working Party on Cervical Cytology Screening. Royal College of Obstetrics \& Gynaecology 1987: London.

8 Kelly BA, Black AS. The inflammatory cervical smear: a study in general practice. $B r \mathcal{F}$ Gen Pract 1990;40: study in

9 Avonts D, Sercu M, Heyerick P, Vandermeeren I, Piot P. Sexually transmitted diseases and Chlamydia trachomatis in women consulting for contraception. Fournal Royal College General Practitioners 1989;39:418-20.

10 Macaulay ME, Riordan T, James JM, et al. A prospective study of genital infections in a family planning clinic Epidemiol - Infect 1990;104:55-61.

11 Malotte CK, Weismeier E, Gelineau KJ. Screening for Chlamydial cervicitis in a sexually active university population. Am f Public Health 1990;80:469-71.

12 Southgate L, Treharne J, Williams R. Detection, treatment and follow-up of women with Chlamydia trachomatis infection seeking abortion in inner city general practice. BMF 1989;299:1136-7.

13 Singer A. Clinical algorithms-The abnormal cervical smear. BMF 1986;293:1551-6. 